Etnográfica

Revista do Centro em Rede de Investigação em

Antropologia

vol. $16(3) \mid 2012$

Vol. $16(3)$

\title{
Procesos judiciales y administrativos de adopción de niños: confrontación de sentidos en la configuración de un "medio familiar adecuado"
}

Judicial and administrative processes about children's adoption: confrontation of diferent senses in the configuration of a "proper family environment"

\section{Carolina Ciordia y Carla Villalta}

\section{(2) OpenEdition}

\section{Journals}

Edición electrónica

URL: https://journals.openedition.org/etnografica/2075

DOI: 10.4000/etnografica.2075

ISSN: 2182-2891

\section{Editor}

Centro em Rede de Investigação em Antropologia

Edición impresa

Fecha de publicación: 1 octubre 2012

Paginación: 435-460

ISSN: 0873-6561

\section{Referencia electrónica}

Carolina Ciordia y Carla Villalta, «Procesos judiciales y administrativos de adopción de niños: confrontación de sentidos en la configuración de un "medio familiar adecuado"», Etnográfica [En línea], vol. 16 (3) | 2012, Publicado el 08 octubre 2012, consultado el 10 febrero 2022. URL: http:// journals.openedition.org/etnografica/2075 ; DOI: https://doi.org/10.4000/etnografica.2075

\section{(c) (7) (8)}

Etnográfica is licensed under a Creative Commons Attribution-NonCommercial 4.0 International License. 


\section{Procesos judiciales y administrativos de adopción de niños: confrontación de sentidos en la configuración de un "medio familiar adecuado"}

\section{Carolina Ciordia y Carla Villalta}

En este trabajo se analizan las tensiones suscitadas entre los agentes del campo de instituciones destinadas a la protección de la infancia cuando el objetivo es proveer a los niños de un "medio familiar adecuado" y para ello se recurre a la adopción. A partir del análisis de casos relevados en nuestros trabajos de campo en el área metropolitana de Buenos Aires (Argentina), analizamos las formas que adquiere el tránsito de los niños hacia la adopción y las interacciones producidas entre los agentes institucionales y las familias de origen de los niños, ya que focalizando en las zonas de negociación y/o confrontación que se abren en ellas es posible identificar diversas tácticas desplegadas por los familiares de los niños a fin de disputar los alcances de la intervención y construir para sí un lugar moralmente aceptable. Desde esta perspectiva, entendemos, es posible complejizar el análisis de las dinámicas de intervención estatal sobre la infancia y sus familias.

PALABRAS CLAVES: adopción, familia, organismos judiciales y administrativos, tácticas.

Judicial and administrative processes about children's adoption: confrontation of diferent senses in the configuration of a "proper family environment" - In this article we analyze the tensions between agents in the field of institutions for the protection of children when the goal is to provide children a "proper family environment" and for that they resort to adoption. From the analysis of cases studied in our fieldwork in the metropolitan area of Buenos Aires (Argentina), we discuss the forms of the trajectories of children towards adoption and the social interactions between institutional agents and the birth families, because focusing on the areas of negotiation and/or open confrontation in them it is possible to identify the tactics deployed by the families of the children in order to contest the scope of intervention and to build for themselves a morally acceptable place. This perspective, we understand, may complexify the analysis of the dynamics of state intervention on children and their families.

KEYWORDS: adoption, family, judicial and administrative bodies, tactics.

CIORDIA, Carolina (carolinaciordia@yahoo.com.ar) - Conicet; Facultad de Filosofía y Letras, Universidad de Buenos Aires, Argentina.

VILLALTA, Carla (carla-villalta@hotmail.com) - Conicet; Facultad de Filosofía y Letras, Universidad de Buenos Aires, Argentina. 


\section{PROVEER A LOS NIÑOS UN "MEDIO FAMILIAR ADECUADO” ES UN} objetivo que atraviesa muchas de las prácticas del circuito jurídico-burocrático destinado, en la Argentina, a la protección de la infancia considerada vulnerable o en riesgo. Por ello, y así como distintos autores han señalado para otros contextos (Vianna 2010; Ribeiro 2009), en el quehacer cotidiano de los juzgados de familia, hogares convivenciales y organismos administrativos de protección de derechos del área metropolitana de Buenos Aires, las acciones que despliegan sus agentes tienen por meta sostener, transformar y/o configurar un orden familiar para esos niños/as. La tarea de "protección" de la infancia remite así en primer término a la evaluación de sus familias, de sus madres, padres, abuelos u otros parientes, es decir de los adultos que son o pueden llegar a ser sus responsables. En esas evaluaciones se intentará determinar si esos niños pueden seguir conviviendo con su familia de origen, si su guarda es transferida a otros adultos, si son ingresados a un hogar o encaminados hacia la adopción. De este modo, aun cuando esos agentes tengan por foco garantizar el "interés superior del niño", sus acciones no pueden comprenderse desligadas de la intervención sobre sus familias.

Estas acciones, no obstante, lejos están de ser desarrolladas por un aparato jurídico con una direccionalidad única que sólo aplica la letra de la ley sobre sujetos pasivos o que desarrolla un control exhaustivo sobre sus conductas. Antes bien, suscitan distintas tensiones entre los agentes encargados de instrumentarlas, y ellas se originan en la confrontación de sus ideales sobre lo que "debe ser" una familia y la crianza de los hijos, de lo estipulado normativamente en términos de derechos de los niños, y de los comportamientos y posibilidades concretas de las unidades domésticas de las que provienen esos niños. Por lo tanto, y contrariamente al enfoque conceptual inspirado en la clásica - y por veces banalizada - obra de Jacques Donzelot (1990), prevaleciente en muchos de los análisis sobre los procedimientos jurídicos y administrativos destinados a los niños en "situación de riesgo", desde nuestra perspectiva centrar el análisis en tales tensiones resulta vital para comprender los modos en que esos ejercicios de poder son desplegados. En otras palabras, si en los estudios sobre las modalidades de gobierno de la infancia ha prevalecido una visión que tendió a sobredimensionar la capacidad de control e intromisión del Estado en la vida familiar, lo que ha llevado a describir esa intervención como homogénea y totalizadora, desde un enfoque etnográfico consistente en el análisis de casos concretos entendemos que es posible dinamizar tal visión y así dar cuenta tanto de los matices de esas acciones como de las contestaciones que tienen por parte de los sujetos a los cuales se dirigen.

Por lo tanto, en este artículo, nuestro interés es analizar algunas de las tensiones suscitadas en este campo institucional cuando el objetivo es proveer un "medio familiar adecuado" a los niños y para ello se recurre a la adopción. Este dispositivo legal, que supone la creación de nuevos vínculos y la extinción 
de otros, se revela fructífero para analizar las valoraciones y significados sobre los lazos familiares, el ejercicio de la parentalidad y la crianza de los niños que sostienen los distintos actores implicados. Para esta indagación centramos el análisis en diferentes casos que hemos relevado en el trabajo de campo desarrollado en juzgados de familia, de menores y en hogares convivenciales del área metropolitana de Buenos Aires, y el material que seleccionamos para ello se compone principalmente de los informes, evaluaciones y actas que conforman los expedientes judiciales y los legajos institucionales de esos niños y niñas.

En efecto, el trabajo de campo que hemos efectuado en los distintos organismos que intervienen en el tránsito de los niños y niñas hacia la adopción, nos permitió conocer y documentar una variedad de rutinas de trabajo, así como acceder a la lectura de los expedientes y legajos en los que, bajo un formato burocrático, se registran las acciones de los distintos agentes institucionales, se caracteriza a las unidades domésticas de los niños y niñas, se informan determinados sucesos que son vistos como significativos, y se fundamentan - a través de informes psicológicos y sociales - las medidas adoptadas. En otras palabras, se construye la historia de esos niños, niñas y familias como un "objeto de administración" (Vianna 2002). A su vez, el trabajo de campo también nos posibilitó comprender que aquello que aparece en el expediente en los registros, actas y demás piezas escritas que lo componen - porta un peculiar valor en este ámbito. "Lo que no está en el expediente, no existe", es una frase que hemos escuchado en repetidas ocasiones, ya sea en charlas informales o en entrevistas, y una buena síntesis del peso que adquiere el registro escrito. Por lo tanto, construir nuestro material de análisis a partir de esos documentos nos ha conducido a indagar qué es lo que queda asentado, cuáles son los significados de aquello que se incorpora o no al expediente, y también para qué y cómo se lo incluye. Desde esta perspectiva, entendemos, es posible ensayar un abordaje etnográfico de estas prácticas escritas que permita contextualizarlas así como dar cuenta de su "poder creador" (Bourdieu 1996). No obstante, si bien construimos gran parte de nuestro material a partir de esos documentos, no de menor importancia para desarrollar este análisis ha sido la interacción cara a cara con los distintos agentes institucionales y el conocimiento de las rutinas de funcionamiento de las diferentes instituciones que intervienen en la determinación de la condición de "adoptabilidad" de un niño.

Ahora bien, en los casos que hemos seleccionado, iniciados todos ellos en el transcurso de los últimos siete años, no hay una "entrega con fines de adopción" en la que generalmente la madre consiente la guarda preadoptiva de su hijo, ni tampoco un abandono "liso y llano" por el cual bebés recién nacidos son dejados en los hospitales donde nacieron y se desconoce el paradero de sus progenitores. Tampoco se trata de niños que ya se encuentran conviviendo con quienes concurren al juzgado para peticionar su adopción. Antes que reflejar situaciones de este tipo, se caracterizan por otros elementos. Por un lado, hay 
una intervención de la justicia que es originada a partir de la denuncia de hospitales y de sus servicios sociales acerca del riesgo en que los niños se encuentran. Por otro, la familia de origen de los niños está presente, por medio de los propios padres, de abuelas o tíos, pero por muy diferentes motivos a lo largo de la intervención institucional es descalificada para hacerse cargo de su crianza. De tal modo, ya sea porque se evalúa que los parientes no tienen "aptitud ni actitud" suficiente, no se comprometen, no se organizan o no pueden brindar un marco estable a esos niños, en el transcurso de la intervención judicial se instrumentan distintas medidas tendientes a modificar sus conductas y ante la imposibilidad de lograrlo, cobra fuerza la idea de que el mejor destino para esos niños es la adopción.

A partir de este recorte procuramos analizar las interacciones que se producen entre los agentes institucionales y las familias de origen de los niños, ya que focalizando en las zonas de negociación y/o confrontación que se abren en ellas, es posible complejizar el análisis de las formas que reviste el tránsito de los niños hacia la adopción. Una figura vista tradicionalmente como una medida de protección a la infancia huérfana, desamparada y abandonada, pero que actualmente - en un escenario en el que tanto la identidad como la convivencia de los niños con su familia de origen, están construidos como derechos que el Estado debe garantizar - se nutre también de otros valores. Por ello antes de emprender nuestro análisis, nos detenemos brevemente en los significados asociados a la adopción en diferentes momentos históricos en la Argentina.

\section{UN TRÁNSITO SINGULAR:}

\section{LOS SENTIDOS Y VALORES ASOCIADOS A LA ADOPCIÓN}

En el repertorio institucional de medidas de protección a la infancia, la adopción ocupó históricamente un destacado lugar. Incluso antes de que fuera incorporada al ordenamiento legal argentino, distintas instituciones se servían de ella bajo la forma de "colocaciones de niños". Ya fuera para descomprimir los establecimientos en los que se albergaba a los niños, proporcionarles una familia de la cual "carecían", o evitar el "inexorable" camino que conducía desde la infancia en peligro hacia una infancia peligrosa, la adopción fue conceptualizada como una medida que permitía completar la salvación de esos niños (Guy 2009; Villalta 2006).

Si bien en la época en que no se encontraba legislada como tal también era considerada un atentado a la familia legítima, lo que llevó a que en 1948 fuera incorporada a la legislación y sólo en su forma "simple", la adopción con el correr de los años fue dotada de mayores connotaciones positivas. ${ }^{1}$

1 Este atentado a la "familia legítima" estaba dado por el hecho de que posibilitara la incorporación a la familia de los denominados "hijos ilegítimos" (aquellos nacidos fuera de la unión [continua] 
Ello se observa, por ejemplo, en los debates que hacia fines de la década de 1960 acompañaron la introducción de la denominada "adopción plena" (Villalta 2010a). Valorada como una suerte de "remedio a todos los males" (Selman 2004), en esos años se enfatizaba la necesidad de que fuera ágil y "temprana" y que el niño adoptado tuviera iguales derechos que los que poseían los hijos biológicos. Además, los distintos agentes que abogaban por su jerarquización y difusión sostenían que era necesario limitar la participación de los padres biológicos en el juicio de adopción, ya que sólo conducía a dilatar el proceso y a generar temor en los adoptantes. ${ }^{2}$ Por lo tanto, en ese contexto, la adopción plena - incorporada a la legislación en 1971 mediante la Ley 19.134 - fue connotada como un decidido avance.

Esta jerarquización de la adopción, entre otras cosas y paradójicamente, daba a los padres biológicos la posibilidad de entregar a su hijo en adopción mediante instrumento público, pero los excluía del juicio de adopción si lo habían desamparado o si, según el "prudente arbitrio judicial", era inconveniente citarlos. Así al igual que sucedía en otras partes del mundo en aquella época (Yngvesson 2007; Ouellette 1998; Fonseca 2002), con este tipo de adopción se intentaba "imitar a la naturaleza" o más precisamente al modelo de reproducción inspirado en el proceso biológico de la procreación sexuada, un modelo basado en el "principio de exclusividad de la filiación", que no hace otra cosa que vehiculizar la idea de que "la filiación es un hecho de la naturaleza, un asunto de la consanguinidad, que se encuentra reforzado por el hecho de que habitualmente los genitores de un niño son aquellos que son designados como sus padres" (Ouellette 1998: 156). De modo que, si según este principio "cada niño no tiene más que una sola madre y un solo padre" (1998: 157), con la adopción plena se privilegiaba abiertamente el rol de los adoptantes haciendo como si los progenitores desaparecieran de la existencia de sus hijos (Fonseca 1998).

Ahora bien, si en ese contexto predominaron las valoraciones positivas en torno a la adopción - en tanto lo que también se cuestionaba era la larga permanencia de los niños en instituciones y los perjuicios que ello les ocasionaba-,

conyugal legal). Por ello, la adopción sancionada en 1948 (Ley 13.252) estipuló un único tipo de adopción, por el cual los niños adoptados no ingresaban en la familia de los adoptantes, es decir no tenían relación de parentesco con sus ascendientes o colaterales. Para un análisis sobre las resistencias en promulgar esa primera ley de adopción, véanse Cosse (2006) y Villalta (2006).

2 En aquellos momentos quienes promovían la adopción planteaban, entre otras cosas, que resultaba conveniente que hubiese una "supresión total del conocimiento de los padres de origen" (Aberastury 1970: 491), y que no era "alentador adoptar a niños de la misma zona, porque no puede asegurarse fácilmente la desvinculación total del hijo adoptivo y su familia de sangre; condición primordial para que los resultados de la adopción sean positivos" (Fernández de la Puente 1970: 500). Tales afirmaciones - vertidas, respectivamente, por una de las pioneras del psicoanálisis infantil en la Argentina, y por una abogada especialista en adopción de niños - permiten entrever cuáles eran los valores asociados a la adopción y fundamentalmente a las familias de origen de los niños "adoptables". 
hacia fines de la década de 1980 se observan otros sentidos y valores en escena. Este nuevo escenario, en la Argentina, no sólo tuvo por bastidores la promulgación de la Convención de los Derechos del Niño y la conformación, por parte de distintos activistas, de un "frente discursivo" sobre su necesaria garantía y exigibilidad, elementos presentes también en otros países de la región (Fonseca y Cardarello 2005; Fonseca 2004), sino también el impacto que produjo la apropiación criminal de niños desarrollada durante el terrorismo de Estado en la Argentina (1976-1983). Este "acontecimiento" (Sahlins 1997), construido como tal por la lucha de Abuelas de Plaza de Mayo, llevó, entre otras muchas cosas, a construir a la "identidad" como un derecho y también condujo a repensar y cuestionar los significados conferidos a la adopción. En esta reorganización de sentidos se resignificó la "adopción simple" a partir de considerar que con ella se resguarda mejor el derecho a la identidad de los niños, se acuñó el término "apropiación", se avanzó en el cuestionamiento a las amplias facultades de los jueces y otros funcionarios, se logró la sanción de una nueva ley de adopción, y también se valorizó el papel de las familias de origen y se otorgó importancia al mantenimiento de los lazos de los niños con ellas (Villalta 2010b).

Este desplazamiento de sentidos, no obstante, lejos estuvo de reemplazar aquellos otros valores dados a la adopción. Antes que eso complejizó aun más un escenario en el que actualmente la adopción debe ser antecedida obligatoriamente por la declaración judicial del estado de "abandono" y de "adoptabilidad”, y en el que - fundamentalmente a partir de la sanción en el año 2005 de una nueva ley denominada de "protección integral de derechos de niños, niñas y adolescentes" - la separación de los niños de su medio familiar "debe ser" una medida de última ratio y las carencias socio-económicas no son razón suficiente para operar esa separación.

En efecto, la sanción de esta nueva normativa que promueve un enfoque de derechos para el diseño e implementación de las políticas destinadas a la infancia; los cuestionamientos a las antiguas prácticas institucionales destinadas a la minoridad que, según se sostenía, conducían a "criminalizar la pobreza" en la medida en que los niños/as eran "tutelados" o separados de su medio familiar en virtud de sus carencias socio-económicas; el surgimiento de nuevos organismos de protección de derechos que asumieron algunas de las atribuciones que antes correspondían al Poder Judicial - tal el Consejo de Derechos de Niños, Niñas y Adolescentes en la Ciudad de Buenos Aires -; y también la implementación de nuevas políticas sociales que apuntan a combatir la pobreza infantil y la vulnerabilidad de los hogares ${ }^{3}$ han contribuido a reconfigurar el campo de

3 Una de las políticas más significativas ha sido la implementación desde noviembre de 2009 de la Asignación Universal por Hijo para la Protección Social que, según distintos estudios, ha contribuido a mejorar notablemente distintos indicadores de bienestar social. Asimismo, es de señalar que desde el año 2003 la Argentina protagoniza un proceso de recuperación socio-económica, luego de una década de predominio de políticas neoliberales que habían conducido al país a una fuerte recesión [continua] 
las políticas para la protección de la infancia. Sin embargo, también han promovido distintas tensiones entre aquellos agentes que deben lidiar con "el cálculo de los varios riesgos involucrados en la elección de los guardadores, tanto en términos de su sustento material, como de su formación moral" (Vianna 2002: 273).

Si bien estas tensiones no son por completo novedosas, consideramos que muchas de ellas actualmente adquieren nuevas formas e intensidad. Así, en el contexto actual en el que los derechos de los niños a su "identidad" y a convivir con su familia biológica cobran preeminencia, el tránsito hacia la adopción se transforma, algunas veces, en un sinuoso camino y un objeto de negociación. En ese tránsito es posible apreciar cómo se expresan diferentes percepciones y disputas de sentidos en torno a lo que es y "debe ser" una familia, y también cómo, en un contexto de profundas desigualdades socio-económicas, las familias de origen de los niños son objeto de una evaluación moral. Esas familias, como veremos a continuación, en muchos casos provienen de las zonas más pauperizadas de la Argentina (por ejemplo, las provincias del noroeste, como Jujuy) o bien de los sectores más vulnerables de países limítrofes (en especial, de Bolivia y Paraguay) que migran a la Ciudad de Buenos Aires.

\section{DE EVALUACIONES Y MEDIDAS}

"Cuando puedan traigan una foto de la nena porque el juez tiene las de todos los niños que dio en adopción”, fue una de las frases que la trabajadora social de un juzgado de familia de la Ciudad de Buenos Aires pronunció al finalizar la audiencia en la cual Elizabeth fue entregada en guarda preadoptiva a un matrimonio. Se abría así una nueva etapa y finalizaba un proceso que había implicado el tránsito de la nena desde un hospital público a un hogar, a la casa de "colaboradores" del hogar y finalmente a la declaración de su estado de abandono y de adoptabilidad. ${ }^{4} \mathrm{Si}$ en esa audiencia las trabajadoras sociales relataron la "historia" de Elizabeth, y así contaron que nació prematura y había pasado la mayor parte de su vida en un hogar, pocos datos hubo mucho menos preguntas - sobre quienes la engendraron. De su progenitora,

y a un quiebre de las formas redistributivas del Estado. Los casos que analizamos en este artículo se sitúan temporalmente en este escenario. De hecho, corresponden a los años 2002 a 2006, 2007, y 2009 hasta la actualidad. No obstante, y como veremos, aun cuando en los últimos años han mejorado los indicadores de empleo, pobreza e indigencia, la mayor parte de las familias que son objeto del tipo de intervenciones aquí analizadas, pertenecen a los estratos más pobres de la población.

4 Los hogares convivenciales - ya sean públicos o pertenecientes a ONG subvencionadas por el Estado - donde son derivados los niños y niñas objeto de una medida de protección, suelen contar con "colaboradores", esto es con personas que voluntariamente concurren a ellos para brindar distintos tipos de "ayuda" (recursos materiales, actividades con los niños, etc.). En ocasiones, esas personas participan del cuidado de los niños, los llevan a sus casas, y eventualmente se les transfiere su guarda. Para un mayor desarrollo de este tema, veáse Ciordia (2010). 
no obstante, quedaron algunos rastros en el expediente judicial que fue configurándose durante la vida de Elizabeth. Algunos vestigios que, bajo la forma de comunicaciones entre los agentes que fueron tomando decisiones sobre el destino de la niña y de informes sociales y psicológicos sobre su madre, posibilitan reconstruir cómo fue el tránsito hacia la adopción de esa niña.

Como en los casos que luego analizaremos, el expediente judicial se originó a partir de la denuncia del hospital adonde su madre concurrió para dar a luz. De tal manera, el contacto con esa instancia estatal fue en buena medida determinante para originar la intervención y configurar la historia de estas familias como una causa judicial. En esas causas judiciales se basa el análisis que presentamos.

\section{Cuando se cumple lo que dice la ley}

En julio de 2007, la Guardia de Abogados del Consejo de Derechos de Niños, Niñas y Adolescentes (en adelante CDNNyA) ${ }^{5}$ del Gobierno de la Ciudad de Buenos Aires recibió una consulta de parte de una trabajadora social del servicio social de un hospital de niños. ${ }^{6}$ En ella informaba la situación de una niña de 3 meses de edad que desde abril se encontraba internada. Si bien no estaba en condiciones de obtener el alta médica, en la consulta se refiere que es "una paciente en situación de riesgo por serias dificultades en el vínculo madrehijo". De esta manera, haciendo referencia a una noción construida en referencia a distintos saberes científicos (como la medicina y la psicología) que tiende a reificar una imagen naturalizada de la maternidad y de la infancia, así como a condensar un particular significado en este ámbito, comienza la intervención. En efecto, evaluando y valorando tal "vínculo" al que se lo considera esencial o, como se consignará en algunos de los sucesivos informes, "intransferible e ineludible" para el adecuado desarrollo del niño, transcurrirán - como veremos en este y en los otros casos - los primeros momentos de la intervención.

Esta comunicación origina entonces un legajo al que son adjuntados distintos informes elaborados durante la internación de Elizabeth. A través de ellos, podemos saber que la niña nació en un hospital del conurbano bonaerense,

5 Este organismo es la autoridad de aplicación de la nueva ley de infancia (Ley 26.061 de 2005). Sus diferentes servicios están facultados para adoptar las medidas de "protección" y de "protección excepcional" que esta nueva ley prevé, y en este último caso dar intervención a la justicia para que controle su legalidad. Las defensorías zonales son la representación del CDNNyA en diferentes barrios de la ciudad de Buenos Aires. Están compuestas por abogados, psicólogos y trabajadores sociales que intervienen en aquellos casos en que los niños, niñas y adolescentes poseen sus derechos amenazados o "vulnerados". 6 Todos los hospitales públicos porteños cuentan con un servicio social integrado mayoritariamente por trabajadores sociales. Su origen se remonta al año 1929, época en la que, plantea Ciafardo (1990), la visitadora o asistente social fue para los médicos el factor principal en la profilaxis de las enfermedades y las perversiones morales. Actualmente desarrollan diferentes tipos de actividades, tales como gestión de subsidios, derivaciones a programas de políticas públicas, evaluaciones para otorgar el "alta social" de pacientes considerados en situación de vulnerabilidad social. 
pero a los tres días fue trasladada junto con su madre a ese hospital pediátrico debido a problemas de salud. También se refiere que Teresa, su madre, es paraguaya, tiene 25 años, reside hace dos años en Buenos Aires y tiene un hijo de 4 años que convive con sus abuelos maternos en Paraguay. Por ello se informa que "la familia es desintegrada", y se desconoce el paradero del padre de la niña, ya que su madre refiere haberse separado de él en los primeros meses de embarazo.

Luego de las primeras semanas de internación, la madre comienza a ausentarse y sólo concurre algunas horas por día. Esta situación alerta a los médicos y al servicio social y, como se observa en los sucesivos informes, unos y otro comienzan a evaluar las características y viabilidad de ese "vínculo materno-filial". Así se consigna: "la madre asiste con escasa frecuencia, manifiesta dificultades laborales con su empleadora y familiares para visitar a su hija (se desempeña como empleada doméstica sin retiro)". También se refiere que Teresa tendría intenciones de trasladar a su niña a Paraguay, para que fuera criada por su madre. Ante esto "se ofrece un espacio terapéutico a fin de trabajar las dificultades presentes en la construcción del vínculo madre-hijo". Aunque ella "lo sostiene", también se informa que "se la percibe con poca predisposición, siempre tiene una excusa o pretexto más importante que le impide quedarse en el hospital". Las evaluaciones siguientes serán del mismo tenor. Así si bien se reconoce que la madre está presente, y que "evidencia preocupación e intención de cuidar a la paciente", también se informa que no está todo lo presente que "debería", y que la niña necesita cuidados que difícilmente puedan ser brindados por esta madre que con "excusas" sobre sus dificultades para ir al hospital necesita ser apuntalada para que pueda cumplir su rol. Así las cosas, el hospital decide dar intervención al CDNNyA a fin de resolver la situación de la niña.

Hasta aquí se pueden ver las sucesivas evaluaciones que dan cuenta de una madre "poco predispuesta", pero también se observan tentativas orientadas a modificar su conducta, a brindarle algún tipo de asistencia material y a fortalecer el "vínculo materno". Aunque poco sabemos de las expectativas y sentimientos de esta mujer, de ella se plantea que tiene un "modo afectuoso" de cuidar a la niña, "le habla y la sostiene con cariño", apreciaciones que posibilitan recrear valores asociados a la "buena maternidad" (Badinter 1981; Hays 1998; Nari 2004) y mantener la intervención - al menos en los primeros tiempos - lejos de un "punto de no retorno" (Vianna 2002). ${ }^{7}$

7 Como distintas autoras han analizado, en la construcción del "ideal materno" han participado distintas disciplinas - tales como la medicina, la puericultura, la pediatría, el psicoanálisis infantil - que con mensajes morales y prescriptivos han conformado parámetros de evaluación de lo que es una "buena madre" que son utilizados de ordinario por los agentes de distintas instituciones. Este ideal, sustentado en la premisa de que el cuidado materno es indispensable para el adecuado desarrollo infantil y para la estructuración psíquica del niño (Hays 1998; Colángelo 2008), [continua] 
El "no retorno" comenzará a perfilarse algunas semanas después cuando, una vez que Elizabeth obtenga el alta médica, su progenitora se presente al hospital con dos amigas y solicite su externación. En el informe elaborado a raíz de esa presentación, se consigna:

"Concurre al Servicio Social la Sra. T junto a dos amigas presentadas como posibles cuidadoras de la niña [...] Refieren vivir en un domicilio cercano al actual de la mamá. Ambas tienen hijos, una de ellas es madre de una niña que ha sido prematura, en su relato se evidencian pautas de alarma respecto al cuidado que requieren los niños nacidos antes de término [...] Da como referente a la licenciada $P$, trabajadora social de la unidad sanitaria 6, Barrio X [...] se les indica que deben dirigirse al CDNNyA a fin de mantener entrevista con la licenciada $\mathrm{A}$, ya que el organismo ha tomado intervención".

Este informe finaliza indicando que dadas las dificultades de Teresa para asumir la función materna, es aconsejable derivar a la niña a un pequeño hogar. De la entrevista que días después mantienen estas mujeres con los profesionales del CDNNyA, también se da cuenta en un extenso informe, en el que se puede leer:

"Se observa una actitud activa y predispuesta de las amigas, la cual se contrapone a aquella presentada por la madre. En efecto, no participa de la charla, salvo cuando se le realizan algunas preguntas [...] además no se muestra convincente en la afirmación de su rol materno, más allá de expresar que quiere conservar a su hija. No logra dar cuenta de planes o proyectos para cuando egrese del hospital. A partir de esto se podría inferir que, sumado a las dificultades materiales para hacerse cargo de Elizabeth, no habría disponibilidad en el espacio psíquico de la madre para albergar a la beba. Teresa se cruzó con amigas y les contó con gran angustia que su beba estaba internada y no tenía quien la ayude para hacerse cargo de ella. Se explicitan estas impresiones, reforzando la idea de que más allá de haber hallado un soporte en estas amigas, debe ponerse en juego la responsabilidad que implica el ejercicio del rol materno ineludible e intransferible en caso de que la niña permanezca a su lado".

[continuação] se asocia a una concepción naturalizada de la familia y fundamentalmente de la maternidad en la cual el "amor materno" es visto como una reacción instintiva de cualquier mujer que haya dado a luz (Badinter 1981). Por ello, como señala Donna Guy (1998) para la Argentina, desde principios del siglo XX las mujeres comienzan a ser evaluadas como buenas madres ya no por la cantidad de niños que puedan dar a luz, sino por la producción de niños saludables, y la mujer más que fidelidad a su marido debe tener fidelidad para con sus hijos. 
Si hasta ese momento Teresa había sido tolerada, ante la inminencia del egreso hospitalario de su niña, las evaluaciones tomarán otro cariz y también es posible apreciar que su actitud se modificará. Por ello, si hasta entonces había concurrido al hospital, ofrecido la alternativa de enviar a su niña a Paraguay con su madre, y conseguido la ayuda de dos amigas, a partir de este momento la presencia de Teresa, al menos en el expediente, comenzará a tornarse más borrosa hasta casi desaparecer.

En septiembre, el CDNNyA dictó una medida excepcional de protección que fue convalidada por la justicia e implicó el ingreso de Elizabeth a un hogar. ${ }^{8}$ De su madre ya no se encuentran referencias. De hecho, en los informes que elabora el hogar se plantea que nunca la ha visitado. En los meses siguientes, el juzgado la cita en dos oportunidades a mantener una audiencia. A ninguna de ellas "comparece". Además, la trabajadora social del hogar informa no haber tenido noticias ni contacto con la familia biológica.

Así las cosas, desde el juzgado se cita nuevamente a Teresa y en esa oportunidad se enfatiza cuál es el objetivo: "a fin de hacer valer sus derechos respecto de la niña", y se aclara: "en caso de incomparendo injustificado, se tendrá por configurado el abandono de Elizabeth". Al mismo tiempo, se solicitan informes al CDNNyA, organismo que formalmente debe realizar un seguimiento de las medidas de protección y, tal como postula la normativa, "propiciar, a través de mecanismos rápidos y ágiles, el regreso de las niñas/os y adolescentes a su grupo o medio familiar y comunitario" (art. 41, inc. b, Ley 26.061).

A partir de este pedido del juzgado, comienza a intervenir otro servicio del CDNNyA, en este caso una de sus defensorías zonales. Transcurridos dos meses de aquel pedido, la defensoría zonal informa:

"Se mantiene entrevista con Teresa (madre de Elizabeth), Alberto y Raúl (tíos maternos). La madre manifiesta que ha dejado de visitarla en el

8 Las medidas excepcionales de protección de derechos, previstas por la ley de infancia del año 2005, implican la separación de los niños de su familia cuando "estuvieran temporal o permanentemente privados de su medio familiar o cuyo superior interés exija que no permanezcan en ese medio" (art. 39, Ley 26.061). A diferencia de las "disposiciones tutelares" y de las medidas de "protección de persona” que regían anteriormente, éstas se encuentran rodeadas de mayores garantías, ya que para adoptarlas deben haberse agotado todas las medidas de protección de derechos que prevé la misma ley, no pueden fundamentarse en "la falta de recursos económicos, físicos, de políticas o programas del organismo administrativo” (art. 41, inc, f, Ley 26.061) y deben ser notificadas a los padres. En el caso de Elizabeth, es interesante notar que este rito formal fue cumplido en tanto se libró una notificación a su madre. Sin embargo, ésta nunca fue entregada, ya que el oficial notificador (empleado judicial encargado de entregar las "cédulas de notificación") expresó: "cumplo en informar que devuelvo la presente cédula sin diligenciar dado que el domicilio indicado se encuentra dentro de una villa de emergencia, zona de alta peligrosidad que, como es de dominio público, debido a los constantes asaltos a mano armada y demás delitos contra las personas y propiedad, es imposible notificar en esa zona por el alto grado de delincuencia”. Así, en función de la peligrosidad de la zona en la cual residía Teresa nunca fue notificada de la medida dispuesta. 
hospital en septiembre porque 'tenía problemas de dinero, falta de trabajo y estaba enemistada con sus hermanos'. Refiere además que 'no sabía qué podía pasar con la bebé después de dejarla en el hospital' haciendo referencia a su desconocimiento en cuanto a procesos legales y/o del Estado relacionados con este tipo de situación. [...] Raúl refiere que hasta el momento en que los profesionales de esta Defensoría se pusieron en contacto con él, 'no tenía idea de la situación, desconocía dónde estaba su hermana y la bebé'. Asimismo, estaría de acuerdo para que la nena y su madre residan en su casa donde convive con su señora y 2 hijos".

Esta posible pero lejana alternativa apareció prontamente inviable. Simultáneamente en el expediente se informa que las trabajadoras sociales del juzgado y de la Defensoría Pública de Menores habían concurrido al hogar, y en la entrevista que mantuvieron con sus profesionales se coincidió en "la necesidad de encarar un trabajo conjunto a fin de lograr una pronta inserción de Elizabeth en un medio familiar".

Sin haber logrado que Teresa "compareciera" al juzgado - más allá de los esfuerzos realizados por los profesionales de la defensoría zonal -, Elizabeth fue declarada en "estado de abandono" y "adoptabilidad", y al mes siguiente entregada en guarda preadoptiva. En esa oportunidad, y antes de solicitar una foto de la niña para el despacho del juez, la trabajadora social del juzgado - una mujer de unos 55 años con una larga trayectoria en el ámbito judicial contó a los cónyuges que, si bien este caso "se podría haber resuelto antes", el juez era "muy cuidadoso". Por lo tanto, podían quedarse tranquilos, porque a ellos sólo les restaba presentarse en seis meses para iniciar el juicio de adopción. Para enfatizar lo que estaba diciendo, expresó: "Además si llega a pasar algo, es el juez el que decide. Esto lo dice la ley".

\section{No les podía haber pasado algo mejor}

Unos años antes de que este caso fuera "resuelto", el mismo juez había declarado el estado de adoptabilidad de tres hermanos. Al igual que Elizabeth, los tres habían nacido en hospitales públicos y los servicios sociales de todos ellos habían dado intervención a la justicia para que resolviera el "alta social".

Si cuando nació Mariano, el mayor, se había informado al juzgado que: "su progenitora carece de los recursos mínimos para hacerse cargo del cuidado del menor", al nacer Sergio y Gabriel se adujeron idénticos motivos para el inicio

9 "Alta social" es un término corriente, en este ámbito institucional, usado para designar la resolución de determinadas situaciones: aquellas en las que el "alta médica” está ya otorgada, pues las condiciones de salud del paciente lo ameritan, pero en las cuales las condiciones sociales y materiales no aconsejan que deje el hospital o más precisamente, en el caso de los niños, que lo deje para convivir con su familia. 
de una medida de "protección de persona" que culminó tres años después. ${ }^{10}$ En ese lapso fueron acumulados al expediente judicial diversidad de informes y registros de comunicaciones entre los organismos que intervinieron en el caso. Allí también, y bajo ese formato burocrático, quedaron rastros de la madre y el padre de los niños, o mejor dicho rastros de lo que los diferentes agentes pensaron sobre ellos, un pensamiento que fue unánime en torno a una cuestión: la madre de los niños no estaba capacitada para afrontar su crianza. Así lo atestiguaron los informes producidos por los servicios sociales hospitalarios y por los distintos organismos intervinientes. En ellos, en términos que casi no ofrecen variaciones, se describía:

"Paciente de 34 años, sin instrucción, soltera, vive en pareja desde hace 3 años con Mario [...] en una habitación de un hotel abonada por subsidio del Gobierno de la Ciudad de Buenos Aires. Debido a que el padre del recién nacido no tiene trabajo, carecen de recursos económicos para cubrir sus necesidades. Reciben una caja de alimentos para la paciente, y su compañero dice comer en la Iglesia. [...] El niño nació el 10/01 [...] Su madre lo cuidó tratando de establecer vínculo, lo logró, pero es observable que tiene dificultades para cumplir con las pautas establecidas por los médicos. Esto demuestra que tiene fallas de comprensión, haciéndose muy difícil establecer una comunicación fluida e intercambiar información [...] La presencia de la madre no es constante debido a la falta de dinero para abonar el transporte, muchas veces han venido caminando desde su domicilio".

Esta mujer, de quien se sospechaba tenía problemas de salud mental, recurrentemente se presentaba en el juzgado junto a su pareja para solicitar la restitución de sus niños. Sin embargo, como la trabajadora social del juzgado se preocupó por dejar asentado en el expediente, Mario, el padre de los niños "si bien manifiesta que su compañera continúa mostrándose angustiada por no tener a su hijo consigo, al explicársele la situación irregular en la que ambos se encuentran con relación al cuidado que merece un pequeño recién nacido, dice entenderlo y reconoce que su compañera no puede hacerse cargo". ${ }^{11}$ También

10 Las medidas de "protección de persona" se encontraban previstas en el Código Civil y Comercial de la Nación y fueron derogadas por la Ley 26.061. Eran adoptadas por la justicia de familia cuando se consideraba que los/as niños/as estaban expuestos/as a "peligros y/o amenazas a su integridad física o moral". Esas medidas no se encontraban limitadas en el tiempo, y fueron objeto de duros cuestionamientos por parte de los activistas que propulsaron la sanción de la nueva ley de infancia.

I I Si como plantea Godelier "el punto más fuerte de un poder de opresión, de dominación, no es justamente el de la fuerza física, sino por el contrario el del consentimiento de los dominados a su dominación" (2004: 110), es sumamente interesante notar que en este registro que realiza la trabajadora social lo que se pone de manifiesto es el consentimiento y comprensión del padre de los niños respecto de las decisiones adoptadas por la justicia, más allá de que luego se opondrá a ellas. En tal caso, se podría pensar, el esfuerzo por dejar asentado ese consentimiento nos habla también de un [continua] 
se consigna: "frente al Sr. se llama a una pariente de la Sra. C con el fin de conocer si podría hacerse cargo del pequeño, obteniéndose como respuesta que no se encuentra capacitada atento la grave situación económica actual". ${ }^{12}$ Así configurada la situación, Mariano y luego Sergio y Gabriel son ingresados al Programa Amas Externas del Consejo Nacional de Niñez, Adolescencia y Familia (Connaf), y a sus padres se les concede un régimen de visitas. ${ }^{13}$ De estas visitas quedarán también constancias en el expediente. En los informes que el programa envía al juzgado abundan distintas apreciaciones sobre los padres, aunque su común denominador es una estructura narrativa que comienza con el reconocimiento del deseo de los progenitores de tener sus hijos consigo, que seguidamente es contrapuesto a la inexistencia de "aspectos mínimos de organización familiar para hacer frente a la crianza”.

Si durante dos años la situación estuvo así configurada, un nuevo suceso la modificará parcialmente: Mario se presenta al juzgado, informa que su mujer falleció y vuelve a solicitar el egreso de sus niños. De allí en más las evaluaciones recaerán sobre este padre, de quien se plantea: "muestra afecto por sus hijos, pero en el tiempo transcurrido no ha podido desarrollar un proyecto de vida que permita su egreso".

En ese lapso, sin embargo, lo que sí parece quedar claro para Mario es la "imposibilidad" de que sus hijos egresen con él. Al menos eso puede inferirse de una nueva presentación que realiza acompañado por su madre. En esa audiencia ambos explican que la mujer, que reside en la provincia de Jujuy, se instalará en Buenos Aires para ayudar a Mario en la crianza de sus niños - una propuesta de otra configuración familiar que, seguramente en función de la nueva negativa a externar a los niños, tomará otros contornos. Así, habiendo transcurrido dos meses de su primera presentación, concurrirán nuevamente al juzgado y la madre de Mario planteará:

"Manifiesta su deseo de hacerse cargo de sus nietos y llevarlos con ella adonde reside en Jujuy [...] Informa que vive en una casa junto con su

[continuação] interés de los profesionales por legitimar la medida que están adoptando, en tanto al conseguir la anuencia del padre no se trataría de una decisión unilateral ni desprovista de fundamentación.

12 Cabe destacar que esta primera intervención se remonta al año 2002, momento en el cual la Argentina transitaba por una de las peores crisis económicas de su historia, con una tasa de desempleo récord que alcanzaba al $21,5 \%$ de su población económicamente activa y con un nivel de pobreza e indigencia que alcanzaba respectivamente al 49\% y $11 \%$ del total de su población. Para mayor información, ver Cepal/UNICEF (2006).

13 Este programa se componía de una dotación de mujeres que recibían en su casa a niños/as de 0 a 4 años "dispuestos" por la justicia. Recibían una paga mensual por cada niño/a, y eran supervisadas por profesionales del programa. Siempre y cuando el juzgado y la dirección del programa lo autorizaran, la familia biológica podía realizar visitas, que se efectuaban bajo la supervisión de los profesionales del programa y no se realizaban en la casa del ama sino en un instituto de menores. 
hermana, su nieta de 30 años, y sus bisnietos de 10 y 8 años. Que trabaja en un comedor comunitario y que su hermana y nieta están dispuestas a cuidar a los niños, propuesta que es compartida por el progenitor. Expresa que cuenta con comodidades en la vivienda para albergar a los niños y que cerca de su casa hay un hospital".

La nueva solución ofrecida por este grupo familiar merece el rechazo del Programa Amas Externas. De tal manera, en un informe elaborado luego de una visita de Mario junto con su madre, se puede leer:

"Se evalúa que el encuentro no brindó resultados positivos dado que tanto Sergio como Gabriel se angustiaron al ver a su familia biológica [...] estuvieron durante todo el encuentro llorando. Mariano fue el único que aceptó sin llorar estar en brazos de su familia biológica. [...] los encuentros de los niños con su padre se llevan a cabo de manera muy irregular [...] en el encuentro del 30/6 se pudo advertir que el Sr. se encontraba con olor a alcohol y tuvo una actitud agresiva con las profesionales. No aceptó que se presente la psicóloga X, refiriendo que no tiene nada que hablar con las profesionales [...] Tiempo antes de culminar ese encuentro se retiró informándole al ama que se iba porque 'si no me van a ojear' (en relación a la mirada atenta de las profesionales). La abuela durante el encuentro se mostró con escasas iniciativas para vincularse y captar la atención de sus nietos".

De esta forma, enfatizando elementos descriptivos tales como el llanto y la angustia, el olor a alcohol, la actitud agresiva y hasta supersticiosa (por su temor a ser "ojeado"), y la escasa iniciativa, el informe concluye:

"El padre no se encuentra en condiciones de hacerse cargo de la crianza de sus hijos y a través de sus actitudes pone obstáculos a las profesionales para realizar un abordaje familiar. Respecto de la abuela se observa que tiene limitadas capacidades para encargarse de la crianza [...] Sumado todo esto a que no se observan acciones concretas más allá del discurso que demuestren el interés familiar en hacerse cargo de los niños [...] por todo lo expuesto, se reitera el pedido de incluir a los niños en un sistema familiar de manera estable y definitiva".

A este informe lo suceden otros, en los que se plantea que Mario, contraviniendo las indicaciones de la profesional, se comunica directamente con el ama con quien conviven sus hijos, y se refiere también la necesidad de que sean ubicados en un "grupo familiar definitivo". Expresada esa necesidad en el expediente, este comienza a girar sobre ella. Así se da cuenta de una audiencia 
que mantienen las profesionales del juzgado con la propia defensora pública, las profesionales de la defensoría pública y del Connaf. Una decisión está siendo confeccionada, y una de sus puntadas finales es dada por la defensora pública quien en un dictamen de fines de 2004 estima que corresponde declarar el estado de adoptabilidad de los niños. Para fundar esa decisión, además de sintetizar los avatares de la intervención, señala:

"a estos niños se les está cercenando un derecho que les es inherente, el de contar con una familia. El prolongar la internación en un hogar sustituto significaría vulnerar este derecho, además de operar en detrimento de su normal desarrollo, atento los prejuicios que una institucionalización prolongada significan en su aparato psíquico".

La "familia", finalmente la encuentran en un matrimonio seleccionado por el juzgado, al que se le adjudica la guarda de Mariano, Sergio y Gabriel. El caso llevó tiempo, pero - al decir de una de las trabajadoras sociales del juzgado - se resolvió de la "mejor manera posible", preservando el vínculo fraterno y cumpliendo con todo lo requerido por la ley. A esos niños, a pesar de todo, como nos decía esta profesional, "no les podía haber pasado algo mejor".

\section{De medidas $e$ incertidumbres}

Registros burocráticos como los analizados hasta aquí no son privativos del ámbito judicial. Ya sea que tomen la forma de expedientes, legajos o carpetas, se encuentran presentes en muchos de los organismos del campo institucional de gestión de la infancia. En esos documentos quedarán cristalizados rastros que nos permiten conocer más que las razones o sentidos de quienes son convertidos en el objeto de la intervención, las razones y formas de actuación de los diferentes agentes institucionales.

El relato que presentamos aquí fue reconstruido, principalmente, a partir del relevamiento de uno de esos documentos: el legajo institucional confeccionado por el hogar en el que Matías se encuentra. Sin embargo, en este caso en lugar de conocer a Matías sólo a través de esos papeles, nuestro conocimiento también es personal, en tanto como parte del trabajo de campo realizado en ese hogar pudimos presenciar los encuentros que se desarrollan entre el niño, su abuela paterna, los profesionales del hogar y una colaboradora que tiene a cargo su crianza.

A diferencia de los dos casos ya presentados, en este aún no se ha "resuelto" el destino de Matías. Además, al reconstruir el tránsito del niño no se encuentran grandes "hitos" y lo que parece caracterizarlo son veladas y silenciosas disputas entre los familiares del niño - que continúan solicitando su "devolución" - y quienes lo tienen efectivamente a cargo: las autoridades del hogar y Natalia, la mujer que se encarga del cuidado cotidiano de Matías desde sus 
6 meses de edad. Tales disputas por la "posesión" del niño se complejizan por la intervención de otros actores institucionales: una defensoría zonal (en adelante DZ) de la Ciudad de Buenos Aires y un juzgado civil de familia.

A su vez, si en los casos anteriores las familias biológicas nunca conocieron a quienes fueron los adoptantes de los niños, en este caso la abuela y Natalia se han encontrado en muchas ocasiones y han intercambiado información acerca de sus vidas y de Matías.

Matías, cuarto hijo de Mariana y primero de Ezequiel, al mes de vida es intervenido quirúrgicamente en un hospital público dado que presentaba una afección pulmonar. Debido a la gravedad del caso, los médicos establecieron un estricto seguimiento ambulatorio. Sin embargo, Mariana no cumplía con los turnos de los especialistas, y además cada vez que asistía "se comportaba de manera escandalosa e inapropiada”. Por lo tanto, el hospital solicitó la intervención del CDNNyA.

Para los agentes de la DZ, dependiente del CDNNyA, la familia de Matías era conocida, ya habían "trabajado" con ella dado que el Equipo de Orientación Escolar del colegio público al que concurrían los tres hijos mayores de Mariana había solicitado su intervención por "las condiciones en que se presentaban los niños". Cuando nuevamente son convocados a intervenir sobre esta familia, acuerdan con los padres de Matías que le cedan su guarda provisoria a Marta, abuela paterna, para que se haga cargo de su cuidado. ${ }^{14}$ Sin embargo, esta primera solución no alcanza su objetivo ya que la madre del niño, quien vivía en el mismo espacio residencial que la abuela - un antiguo centro comercial ocupado ahora por distintos grupos familiares -, en varias ocasiones había "retirado por la fuerza" al niño de la casa de Marta. A la DZ concurrió entonces Marta e informó esta situación y también su preocupación por el hecho de que su nuera no le brindaba a Matías los cuidados necesarios por su estado de salud. Así, este servicio comienza a procurar otras soluciones. Por un lado, realiza gestiones en un programa del gobierno local para que Marta se pueda mudar a otra casa. Por otro lado, se contactan con los abuelos maternos del niño. Sin embargo, ninguna de las dos gestiones dio los resultados esperados.

De tal modo, la DZ decide adoptar una medida excepcional de protección y derivar a Matías al hogar X pero manteniendo el vínculo con su abuela. ${ }^{15}$

14 A partir de la intervención de la DZ, los 3 niños de 12, 9 y 2 años pasan a estar bajo el cuidado de un tío paterno. Según lo relatado por Marta, la escuela habría llamado la atención a la madre dado que las niñas no concurrían regularmente a la escuela, y cuando lo hacían se presentaban sin comer y en condiciones de pésima higiene. Cabe aclarar que esta medida no implicó que Mariana dejara de tener contacto con sus hijos. A su vez, la DZ también intentó gestionar recursos (programas habitacionales y subsidios), algunos de los cuales no pudieron concretarse porque - según refieren los profesionales de ese organismo - los padres nunca completaban la documentación necesaria para tramitarlos.

15 Esta institución se encuentra ubicada en el segundo cordón del conurbano bonaerense; esto implica que el traslado de la abuela hasta allí conste de tres boletos (un pasaje en colectivo, [continua] 
Y ello porque, desde su perspectiva, la medida excepcional tenía como objetivos: "despegar [a Matías] de la historia de la familia" de la madre, que retomara su tratamiento en el hospital, y también que su abuela paterna consiguiera una vivienda adecuada a las necesidades del niño y alejada de sus padres. En definitiva, para este servicio y en aquel momento, la abuela era visualizada como la futura responsable del niño.

Sin embargo, si esta abuela era una opción viable, una vez que entra en escena el hogar se inicia un lento proceso en el que gradualmente comienza a ser descalificada. Si ello es observable en los informes que describen los comportamientos de esta mujer, también se verifica en otras actitudes, gestos y palabras que, en las interacciones con ella, los profesionales del hogar despliegan - una dimensión de micro-prácticas que forma parte de las diversas maneras de señalarle a un familiar que no es bien recibido en la institución o de disuadirlo en sus planes. Estas prácticas, que no son exclusivas de este hogar, conforman una suerte de rutina institucional en relación a las personas que efectúan las "visitas" a los niños y tienen en muchos casos un objetivo disuasorio (rigidez o reducción del horario de visita, espacios delimitados en donde estas se llevan a cabo, prohibición de realizar determinadas actividades con los niños, etc.), lo que genera - en algunos casos - que los vínculos entre los familiares y los niños comiencen a socavarse. Ejemplo de ello es lo que Marta nos contaba respecto de la prohibición de sacarle fotos a su nieto durante la fiesta de cumpleaños del primer año de vida que se realizó en la institución (que fue organizada por Natalia según consta en el legajo del niño). Así relataba que se lo dijeron de muy mala manera y que esto la desanimó, "me hicieron sentir mal, muy mal". Y, para dar cuenta de su perplejidad, decía: "Mi Mati no es un presidiario, ni hijo de presidiarios. ¿Por qué no puedo tener una foto del cumpleaños de mi nieto?" (Ciordia 2010).

En los primeros informes elaborados por el hogar se puede leer que Matías no tuvo los controles ni el tratamiento médico adecuado, que su familia es boliviana y vive junto a otras familias de la misma nacionalidad, que ésta no tiene "ingresos laborales conocidos", sus condiciones habitacionales son inadecuadas, y que la abuela "tampoco pudo hacerse cargo del bebé y brindarle las condiciones de alimentación, higiene, vestimenta y controles médicos que su situación requiere".

Además, al poco tiempo de haber ingresado al hogar, la directora solicitó autorización para que Matías pueda realizar salidas junto a una colaboradora de la institución aclarando que ello no perjudicaría el vínculo de Matías con su abuela. La DZ autorizó esas salidas y estableció que sean los profesionales del hogar quienes "dirijan y supervisen ese vínculo".

[continuação] otro de tren y un último colectivo). Estos trayectos suman una hora y media de viaje en condiciones regulares, es decir, sin tener en cuenta los habituales inconvenientes que se presentan en el servicio de trenes (interrupciones de la línea por accidentes, servicios limitados, etc.). 
A partir de ese momento, tanto Natalia como la abuela comienzan a estar presentes en cada uno de los informes que se envían a la DZ y al juzgado. Así, Natalia - una docente de 35 años, soltera, que vive en el conurbano bonaerense junto a sus padres - aparece brindándole al niño "bienes de cuidado": se presenta todos los días en el hogar luego de trabajar, colabora en los cuidados del niño, juega con él "mostrando dedicación para estimularlo" y organizó - como señalamos - el cumpleaños del niño en la institución. ${ }^{16}$ A su vez, se informa que corrieron por su cuenta los "remises" hasta el hospital cada vez que Matías asistió a sus múltiples turnos médicos y que abonó unas vacunas que los médicos aconsejaron dado su estado de salud.

La abuela, por su parte, también aparece retratada en esos informes, en los que se informa las visitas que realiza y se evalúa tanto la cantidad de días que asiste, como la calidad del tiempo que dedica a su nieto. A los "bienes de cuidado" ofrecidos por Natalia, se contraponen las visitas efectuadas por Marta: cada quince días durante treinta minutos y "sin poder" cumplir con los días de visita semanales acordados. Además, si bien la directora informa que le han ofrecido "asistencia para interactuar con su nieto", observa que "no logra que el niño permanezca a su lado". Y más allá de que le hayan sugerido que participe de las actividades cotidianas del niño (el almuerzo, el baño), no cumple con ello dado el escaso tiempo que permanece en el hogar. Por lo tanto, nuevamente se estima que Marta "no reconoce el estado de salud [del nieto] y los cuidados que requiere". Además, aun cuando informan que consiguió mudarse, aclaran que la nueva vivienda se trata de "otra casa tomada", y también que en una entrevista habría reconocido lo que los profesionales del hogar sospechaban: su hijo y nuera convivirían con "personas vinculadas a la venta de drogas y armas, además de otras actividades ilícitas".

Con estos elementos se completa un cuadro en el que los diferentes adultos que podrían ser los "responsables" de Matías se encuentran en posiciones sociales claramente asimétricas. No sólo en el plano social y material, sino también en el moral, ya que a partir de las exhaustivas descripciones de sus modos de ser y de hacer, sus comportamientos y acciones son construidos, a través de un lenguaje que se trama en el registro de las emociones y los sentimientos (Vianna 2010), como moralmente correctos o incorrectos, y los diferentes sujetos aparecen - y componen una imagen de sí - como capaces o incapaces.

Ese registro también es utilizado por la familia biológica de Matías, por ejemplo, por su abuela, quien cada vez que asiste a ver a su nieto le lleva alimentos (yogures, jugos de fruta, snacks), aquellos que considera "nutren" al niño y también le gustan; quien también le regala juguetes y - como ella misma

16 Recordemos que Matías era un bebé de pocos meses de vida, por lo tanto, para la institución representaba destinar a una persona para que le brindara cuidado personalizado. 
nos relatara - guarda en su casa objetos que sigue adquiriendo para que su nieto los use cuando esté nuevamente bajo su responsabilidad. Paralelamente a estas acciones también inició otras, tendientes a restablecer su imagen como persona aceptable frente a los ojos de los administradores, y así, por ejemplo, se presentó en la DZ y contó que había arreglado el baño para que Matías pudiera ir a vivir con ella.

La madre de Matías también intenta configurarse como una persona "moralmente aceptable". Así, habiendo transcurrido un año y medio del inicio de la intervención, concurre al juzgado para pedir que Matías retorne a su grupo familiar. En esa ocasión, presenta, a través de un abogado - requisito judicial para que su voz sea tenida en cuenta - , un escrito informando que inició un tratamiento psicológico, al que es acompañada por su padre y hermana, y solicita una audiencia. ${ }^{17}$

A esa audiencia, que es celebrada en el juzgado, se presentan los padres, la abuela paterna, el abuelo materno y la tía materna de Matías y solicitan que su guarda sea transferida a la abuela paterna. Sin embargo, los profesionales de la DZ - aun reconociendo que el vínculo con la abuela es "positivo" para el niño - sostienen que todavía "no es el momento" para que retorne con su grupo familiar, y junto a las profesionales del hogar no prestan su conformidad. En consecuencia, el juzgado no hace lugar a la petición y la medida de protección sigue "en curso".

A los pocos meses, los padres de Matías realizan otro intento y solicitan autorización esta vez para visitar a su hijo en el hogar. Antes de resolver, el juez pide al hogar que evalúe la conveniencia de esas visitas - una evaluación que estima que la presencia de "los padres podría ocasionarle tensión emocional ya que no los reconoce dada su temprana desvinculación”, y por lo tanto sugiere denegar lo solicitado.

Mientras tanto, y lejos de tribunales y audiencias, Natalia continúa con sus cotidianas tareas de cuidado de Matías, tareas que redundan, a casi dos años de su vinculación con él, en un fuerte lazo afectivo y un deseo que se instala y se acompaña de acciones y de inversiones concretas y positivamente valoradas por los distintos agentes institucionales. Desea adoptar al niño.

Sin embargo, aún prevalecen las incertidumbres y los resquemores, y si bien el hogar ha sugerido que lo mejor para Matías sería la declaración de su abandono y adoptabilidad, la disputa por la posesión del niño aun no se ha zanjado.

17 El servicio de psiquiatría del Hospital donde Mariana llevaba a su hijo le diagnostica "trastornos psiquiátricos" y aconseja la realización de tratamiento. Si bien en un principio se negó, Marta relató que ella misma la convenció y acompañó a la primera sesión. Marta logra convencer a Mariana utilizando la misma herramienta disciplinaria que había recaído anteriormente sobre ellos: si ella no comenzaba el tratamiento, posiblemente Margarita - segunda nieta por parte de Mariana y de su hijo - también sería ingresada al hogar y separada de sus padres. 


\section{INTERACCIONES, FAMILIAS Y MORALIDADES}

"Son familias en las que si buscás, algo vas a encontrar", nos decía hace unos años una abogada que de esta forma criticaba las intervenciones que, según ella y muchos otros activistas, formaban parte de lo que se cuestionó como "judicialización de la pobreza". No obstante el tono crítico, creemos que la frase sintetiza una de las mayores tensiones que enfrentan los agentes de este campo institucional: la de lidiar con familias en situación de pobreza y/o de extrema pobreza y así tener que ponderar si sus conductas, que distan bastante del modelo normal y aceptable de crianza de los hijos, son producto de las limitaciones impuestas por la miseria o si esos comportamientos revelan "actitudes negligentes" que justifican que los niños sean desplazados de su medio familiar.

Con esas "otras" familias, estos agentes se confrontan e interactúan cotidianamente. En esas interacciones tratarán de aconsejar, persuadir y transformar, pero también en ellas los familiares de los niños negociarán, impugnarán y disputarán sentidos. De tal manera, si bien esas relaciones son claramente asimétricas, ello no nos debería hacer perder de vista que tales interacciones constituyen una pieza central y que los sentidos producidos en ellas definen también los límites y alcances de las variadas intervenciones institucionales.

Ahora bien, analizar estas interacciones a través de registros burocráticos nos debe conducir a ensayar algunos recaudos metodológicos. Ciertamente, en esos documentos, prevalece una "mirada institucional" a través de la cual las familias son retratadas y "dicen" sólo aquello que estiman necesario asentar y registrar los agentes institucionales. Por lo tanto, ejercitar un enfoque etnográfico para leer esos textos implica, entre otras cosas, dar cuenta de sus condiciones de producción (para, por quién y para qué son producidos, en qué momento de la intervención), y detectar los indicios que nos permitan acceder a esas acciones - de convencimiento, de amenaza o de acuerdos - que en tanto no se encuentran reflejadas en esa materialización burocrática, deben ser leídas entrelíneas (Vianna 2002).

Esta lectura, en nuestro caso, se complementó también con la interacción cara a cara que entablamos en nuestros trabajos de campo con los agentes institucionales y con los destinatarios de esas medidas. Y ello, como señalamos antes, no sólo nos permitió comprender la centralidad que adquiere lo que se deja asentado en un expediente o legajo, sino también y principalmente nos posibilitó comprender que unos y otros - quienes aplican tales medidas y quienes las evaden, aceptan o resisten - no son otra cosa que personas de "carne y hueso", personas que, como hemos visto en los casos analizados, construyen y disputan "moralidades" (Howell 1997; Vianna 2010) y a partir de esa construcción traman, legitiman y justifican sus acciones.

En esa dimensión se inscriben las evaluaciones producidas por los distintos agentes institucionales respecto de las familias de los niños. De tal forma, 
reconocer que la madre de Elizabeth le habla y la sostiene con cariño, que Mario siente afecto por sus hijos, o que fue la abuela de Matías quien concurrió a la defensoría preocupada por el trato que su nuera daba a su nieto, son elementos que intentan componer un lugar moralmente aceptable para esos "responsables". Son enunciados que junto a las tentativas de sostener en su rol a esos parientes redundan en el diseño de estrategias orientadas a transformar sus conductas, y así se propondrán espacios terapéuticos, visitas y se realizarán gestiones para conseguir recursos materiales que ayuden a paliar la desventajosa situación socio-económica de esas familias. Son acciones y narrativas que permiten, al menos en los primeros momentos de la intervención, dilatar la configuración del "abandono".

Sin embargo, si esas estrategias tendientes a apuntalar, a fortalecer el "vínculo madre-hijo" y a incentivar la conformación de un "proyecto de vida", tópicos asociados a una determinada moralidad que aboga por el "gobierno de sí" (Foucault 2007) y por una transformación individual, no arrojan los resultados esperados, si a pesar del tiempo transcurrido las conductas no se modifican, el tono de las apreciaciones adquirirá otro cariz. Así, al amor abstracto y al deseo discursivo, se le opondrán otros elementos y las evaluaciones adquirirán un tono moralizante ya que, en definitiva, estas familias "no pueden", se muestran "poco predispuestas", "no se organizan".

Si como dijéramos son estas las apreciaciones que hegemonizan los registros burocráticos, es posible no obstante hallar en ellos rastros de las tácticas - esto es, de prácticas que actúan en "el terreno que le impone y organiza la ley de una fuerza extraña” (De Certeau 1996: 43) - desarrolladas por esas familias a fin de disputar los sentidos con los que están siendo dotadas. ${ }^{18}$ Así, en un plano, estas tácticas se traducen en distintas acciones: en el caso de la madre de Elizabeth, presentar dos amigas que la asistirán en su crianza - haciendo evidente que la crianza puede ser pensada no sólo como una obligación materna individual e intransferible -; idear la alternativa de trasladarse con sus hijos a Jujuy, como hizo Mario; o concurrir al juzgado para solicitar la restitución de su hijo junto a otros integrantes de su familia y con el certificado que acreditaba el inicio de un tratamiento psicológico, tal el accionar de la madre de Matías. Pero también aducir falta de trabajo y dinero para explicar la desvinculación con su hija, como enuncia Teresa, en tanto no era el desinterés el que guiaba su conducta - confrontando así el lugar de "mala madre" que los profesionales

18 La distinción que realiza De Certeau (1996) entre estrategias y tácticas le permite articular un abordaje que complejiza la dominación y la politicidad de lo cotidiano, cuyo signo es el conflicto y las tensiones, y no la introyección del orden o la pasividad. No obstante, aun cuando el peso que le otorga a las acciones de los sujetos podría ser interpretado como un exceso de indeterminación, su punto de partida es el reconocimiento de la desigualdad social. De modo que lo que intenta iluminar son los modos en que, en el marco de esa desigualdad, los sujetos encuentran intersticios donde operar de modos divergentes. 
estaban delineando -; o regalar juguetes y llevar snacks como hace Marta en las visitas que realiza a su nieto, a fin de reafirmarse en su rol de abuela, constituyen huellas que nos permiten apreciar cómo esos familiares intentan componer un lugar socialmente aceptable. Desde esta perspectiva también el hecho de concurrir a dar a luz a hospitales públicos diferentes para intentar evadir la acción de la justicia, como hicieran Mario y su mujer, o comunicarse con el ama que criaba a sus hijos en lugar de hacerlo con la profesional de ese programa, aparecen - si los analizamos a contraluz de los sentidos con los cuales se exponen en los informes institucionales - comunicando otros sentidos. Así estas prácticas pueden ser interpretadas como tácticas tendientes a constituir una imagen de sí y a sus acciones como moralmente aceptables. Son tácticas que ciertamente dilatan, tensionan, y oponen otros sentidos a los que traman sobre ellas los variados agentes institucionales, pero que no obstante - al menos en el tipo de casos que hemos analizado - difícilmente alcancen a revertir aquella potente configuración moral que es central para dilucidar el destino de los niños: el "abandono" y la "adoptabilidad".

\section{CONSIDERACIONES FINALES}

A partir del análisis realizado, hemos intentado identificar las formas e intensidad que adquieren las tensiones que se suscitan cuando la gestión de la infancia tiene por meta la adopción. Si como hemos planteado estas tensiones no son nuevas, sí lo son determinadas narrativas que, en los últimos años, han conformado un potente discurso tramado en términos de derechos de los niños que el Estado debe garantizar.

La importancia dada al mantenimiento de los lazos con la familia biológica, el derecho a la identidad, la no judicialización de situaciones de pobreza junto con las críticas a la separación arbitraria de los niños de su medio familiar han sido tópicos centrales de este nuevo discurso que ha nutrido recientes reformas normativas e incidido en las prácticas desplegadas por muchos de aquellos agentes. Por ello, cuando las familias de los niños no sólo se encuentran presentes sino también los reclaman, las tensiones mencionadas adquieren una mayor intensidad. En esos casos la intervención puede dilatarse y pueden ensayarse otras alternativas en tanto, tal como estipulan las actuales "narrativas hegemónicas”, se debe mantener el vínculo con sus familias biológicas. Sin embargo, en las prácticas cotidianas - en otras palabras, cuando esas narrativas dejan lugar a la aparición de las familias "reales" - se puede observar que gradualmente los consejos y sugerencias devienen en veladas amenazas o abiertas imposiciones, y las evaluaciones comienzan a nutrirse de valores morales tendientes a corroborar lo negativo del mantenimiento de ese vínculo.

En este escenario en el que los derechos de los niños deben ser garantizados y el "abandono" debe declararse y estar "fundado", pareciera cobrar una mayor 
intensidad la descalificación moral de la que son objeto sus familias (Fonseca y Cardarello 2005), ya que si la pobreza no puede ser causal para operar la separación de su medio familiar, las evaluaciones sobre esas madres, padres o abuelos se extreman al punto tal que, en un momento de la intervención, pasa a primer plano la incapacidad para estructurar un proyecto de vida, la falta de espacio psíquico para albergar a un hijo, el olor a alcohol, las actividades ilícitas y el no reconocimiento de los cuidados que un niño requiere. Esos argumentos no son novedosos, y aunados a las valoraciones positivas sobre la adopción, los eventuales adoptantes y al hecho de cumplir con todos los procedimientos estipulados por la ley, permiten dirimir la negociación y zanjar disputas sobre la posesión de los niños.

No obstante, como también hemos intentado demostrar, las amenazas e imposiciones lejos están de aplicarse sobre sujetos pasivos. En efecto, aun cuando sean frágiles, desarticuladas, o al decir de De Certeau, minúsculas, y retomen y utilicen la retórica con la que están siendo juzgadas sus conductas, los familiares de los niños articulan distintas prácticas discursivas y no discursivas para oponerse a las evaluaciones y al cariz que toma la intervención. De tal modo, si ejercitamos nuestra mirada etnográfica en el análisis de estas dinámicas de intervención, podremos captar las complejidades de estos procesos para dar cuenta ya no de la intervención del Estado cual una omnisciente "policía de las familias", sino antes bien de las diversas formas en que ella se configura en las interacciones cotidianas entre distintos agentes estatales, los niños y sus familias.

\section{BIBLIOGRAFÍA}

ABERASTURY, Arminda, 1970, “Adopción”, Revista Jurídica La Ley, 138: 491-494.

BADINTER, Elizabeth, 1981, Existe el Amor Maternal: Historia del Amor Materno, Siglos XVII al XX. Barcelona, Paidós.

BOURDIEU, Pierre, 1996, "Espíritus de Estado: génesis y estructura del campo burocrático", Sociedad, 8: 5-29.

CEPAL/UNICEF, 2006, "Efectos de la crisis en la Argentina: las políticas del Estado y sus consecuencias para la infancia”. Cepal/UNICEF, disponible en: < http://www.unicef.org/ argentina/spanish/Efectos_Crisis_en_Argentina_-_Documento_de_Difusion.pdf $>$.

CIAFARDO, Eduardo, 1990, Caridady Control Social: Las Sociedades de Beneficencia en la Ciudad de Buenos Aires, 1880-1930. Buenos Aires, Facultad Latinoamericana de Ciencias Sociales (Flacso), tesis de maestría. 
CIORDIA, Carolina, 2010, "Entre el pedido de soluciones viables a los padres y la disposición del niño por parte del juez: las distintas formas de gestión de la infancia”, Actas de las VI Jornadas de Investigación en Antropología Social. Buenos Aires, Facultad de Filosofía y Letras de la Universidad de Buenos Aires, 1-18.

COLÁNGELO, Adelaida, 2008, "La construcción médica del niño y del cuerpo infantil: los discursos y las prácticas de la pediatría y la puericultura entre 1890 y 1930", Jornada Historia de la Infancia en Argentina, 1880-1960. Buenos Aires, Universidad Nacional de General Sarmiento, 1-8.

COSSE, Isabella, 2006, Estigmas de Nacimiento: Peronismo y Orden Familiar, 1946-1955. Buenos Aires, Fondo de Cultura Económica.

DE CERTEAU, Michel, 1996, La Invención de lo Cotidiano I: Artes de Hacer. México, Universidad Latinoamericana.

DOnZElot, Jacques, 1990, La Policía de las Familias. Valencia, Pre-textos.

FERNÁNDEZ DE LA PUENTE, Susana, 1970, “Adopción”, La Ley, 138: 499-504.

FONSECA, Claudia, 1998, Caminos de Adopción. Buenos Aires, Eudeba.

FONSECA, Claudia, 2002, "Inequality near and far: adoption as seen from the Brazilian favelas”, Law \& Society Review, 36 (2): 101-134.

FONSECA, Claudia, 2004, "Os direitos da criança: dialogando com o ECA", en Claudia Fonseca, Veriano Terto Jr. y Caleb Faria Alves (orgs.), Antropologia, Diversidade e Direitos Humanos: Diálogos Interdisciplinares. Porto Alegre, UFRGS Editora, 103-1 15.

FONSECA, Claudia, y Andrea CARDARELlO, 2005, "Derechos de los más y menos humanos", en Sofía Tiscornia y María Pita (orgs.), Derechos Humanos, Tribunales y Policías en Argentina y Brasil. Buenos Aires, Antropofagia, 9-41.

FOUCAULT, Michel, 2007, "La 'gubernamentalidad”", en Gabriel Giorgi y Fermín Rodríguez (orgs.), Ensayos sobre Biopolítica: Excesos de Vida. Buenos Aires, Paidós, 187-215.

GODELIER, Maurice, 2004, "Poder y lenguaje: reflexiones sobre los paradigmas y las paradojas de la legitimidad de las relaciones de dominación y opresión”, en M. Boivin, A. Rosato y V. Arribas (orgs.), Constructores de Otredad. Buenos Aires, Antropofagia, 1 10-1 14. GUY, Donna, 1998, "Madres vivas y muertas, los múltiples conceptos de la maternidad en Buenos Aires", en D. Balderston y D. Guy (orgs.), Sexo y Sexualidades en América Latina. Buenos Aires, Paidós, 227-256.

GUY, Donna, 2009, Women Build the Welfare State: Performing Charity and Creating Rights in Argentina, 1880-1955. Durham y Londres, Duke University Press.

HAYS, Sharon, 1998, Las Contradicciones Culturales de la Maternidad. Madrid, Paidós.

HOWELL, Signe, 1997, "Introduction", en Signe Howell (org.), The Ethnography of Moralities. Londres y Nueva York, Routledge, 1-22.

NARI, Marcela, 2004, Las Políticas de la Maternidad y Maternalismo Político, Buenos Aires, 1890-1940. Buenos Aires, Biblos.

OUELLETTE, Françoise-Romaine, 1998, "Les usages contemporains de l'adoption", en Agnès Fine (org.), Adoptions: Ethnologie des parentés choisis. París, Editions de la Maison des Sciences de l'Homme, 153-176.

RIBEIRO, Fernanda Bittencourt, 2009, "Acolhimento de famílias e modos de apoio à (pluri) parentalidade", trabajo presentado en el workshop "A circulação de crianças: revisitando o ‘interesse prioritário’ da criança”, 11-13 de junio, Río de Janeiro, Brasil.

SAHLINS, Marshall, 1997, Islas de Historia, La Muerte del Capitán Cook: Metáfora, Antropología e Historia. Barcelona, Gedisa. 
SELMAN, Peter, 2004, "Adoption: a cure for (too) many ills", en Fiona Bowie (org.), Cross-cultural Approaches to Adoption. Londres y Nueva York, Routledge, 257-273.

VIANNA, Adriana, 2002, "Quem deve guardar as crianças? Dimensões tutelares da gestão contemporânea da infância”, en Antonio Carlos de Souza Lima (org.), Gestar e Gerir: Estudos para Uma Antropología da Administração Pública no Brasil. Río de Janeiro, RelumeDumará, 271-312.

VIANNA, Adriana, 2010, "Derechos, moralidades y desigualdades. consideraciones a partir de procesos de guarda de niños", en Carla Villalta (org.), Infancia, Justicia y Derechos Humanos. Buenos Aires, Universidad Nacional de Quilmes Editorial, 21-72.

VILlalTA, Carla, 2006, De Entregas y Secuestros: La Apropiación de Niños por Parte del Estado. Buenos Aires, Facultad de Filosofía y Letras de la Universidad de Buenos Aires, tesis de doctorado en Antropología Social.

VILLALTA, Carla, 2010a, "Imitar a la naturaleza: la adopción de niños en los años '60: entre ficciones legales y prácticas consuetudinarias”, en Isabella Cosse, Karina Felitti y Valeria Manzano (orgs.), Los 60’ de Otra Manera: Vida Cotidiana, Género y Sexualidades en la Argentina. Buenos Aires, Prometeo, 89-129.

VILLALTA, Carla, 2010b, "De los derechos de los adoptantes al derecho a la identidad: los procedimientos de adopción y la apropiación criminal de niños en Argentina”, Journal of Latin American \& Caribbean Anthropology, 15 (2): 338-362.

YNGVESSON, Barbara, 2007, "Parentesco reconfigurado no espaço da adoção", Cadernos Pagu, 29: 111-138. 